Res Publica Revista de Historia de las Ideas Políticas

ISSN: $1131-558 \mathrm{X}$

\title{
Los principios de disponibilidad e inmediatez en la vicepresidencia latinoamericana
}

\author{
Ariel Sribman Mittelman ${ }^{1}$
}

Recibido: 08-06-2020 / Aceptado: 26-01-2021

Resumen. Numerosos elementos de nuestros sistemas políticos cuentan con un fundamento teórico, con un estudio profundo de los principios teóricos y prácticos que explican su adopción. Por el contrario, la vicepresidencia ha recibido muy escasa atención, aún en países donde esa institución ha ido incrementando su peso político. La combinación de ese gran peso con la mencionada falta de sustento teórico produce notables desviaciones en los análisis de la institución y su desempeño: procuran estudiar el fruto sin conocer las raíces. El objetivo de este artículo es realizar un primer esfuerzo de reflexión teórica en este ámbito, analizando la vicepresidencia en sistemas presidencialistas a la luz de dos principios teóricos: el de inmediatez y el de disponibilidad del poder.

Palabras clave: vicepresidencia; sucesión; América Latina; Estados Unidos; inmediatez; disponibilidad.

\section{[en] Succession to Power and the Principles of Availability and Immediacy. From Medieval France to the Contemporary Latin American Vice Presidency}

\begin{abstract}
Many elements of our political systems have a theoretical foundation, a profound study of the theoretical and practical principles that explain their adoption. On the contrary, the vice presidency has received very little attention, even in countries where this institution has been gaining remarkable political weight. The combination of this weight with the aforementioned lack of theoretical support produces notable deviations in the analyses of the institution and its performance -they try to study the fruit without knowing the roots. The aim of this article is to carry out a first theoretical reflection in this field, analysing the vice presidency in presidential systems in light of two theoretical principles -immediacy and availability of power.
\end{abstract}

Keywords: Vice presidency; Succession; Latin America, United States, Immediacy, Availability.

Sumario. 1. Introducción. 2. La literatura teórica sobre la vicepresidencia. 3. Los principios de disponibilidad e inmediatez en los albores de la Edad Moderna. 4. Entre la Edad Media y las independencias americanas: la filosofía política moderna. 5. Los principios del presidencialismo: indisponibilidad e inmediatez. 6. La vicepresidencia en América Latina. 6.1. Cuatro casos de estudio. 7. Conclusiones. Bibliografía.

Cómo citar: Sribman Mittelman, A. (2021). Los principios de disponibilidad e inmediatez en la vicepresidencia latinoamericana. Res Publica. Revista de Historia de las Ideas Politicas, 24(2), 163-171.

\section{Introducción}

Los estudios sobre la vicepresidencia en América Latina se encuentran actualmente en transición. De haber sido ignorada por la Ciencia Política hasta hace apenas un lustro, esta institución ha comenzado a recibir atención por parte de la comunidad académica de manera recien- te; y la profusión de conflictos vinculados a los vicepresidentes que se han producido en numerosos países latinoamericanos permite augurar que esa atención irá in crescendo. Estas primeras muestras de interés han ido mayoritariamente en una misma dirección: el estudio del 
desempeño vicepresidencial en las últimas décadas ${ }^{2}-$ se suele tomar como inicio del horizonte temporal el retorno a la democracia de gran parte de América Latina durante la Tercera Ola de democratización, durante la década de 1980-. Es decir, se ha tratado fundamentalmente de analizar en qué medida ha cumplido con su principal función: la sucesión del Ejecutivo; con qué frecuencia ha sido fuente de conflictos; cómo se han conformado las fórmulas presidente-vice; qué papel han jugado en el Ejecutivo y en el Senado (en aquellos países donde el vicepresidente preside la Cámara Alta). Por el contrario, un aspecto que nunca se ha abordado es el fundamento teórico sobre el que se asienta. ¿A qué principios debe responder? ¿Qué debates teóricos la sostienen? ¿En qué principio se basa el hecho de que el presidente no pueda -en ningún país- remover al vice? ¿O acaso no se basa en principio alguno? Y si así fuere, ¿no es imprescindible subsanar esta falta? Sin dar respuesta a estas preguntas resulta imposible evaluar el desempeño de la institución en un determinado país; se hace inviable entenderla en toda la profundidad necesaria.

En rigor de verdad, tampoco se han abordado estas bases filosóficas de la vicepresidencia en Estados Unidos, donde los estudios sobre este cargo cuentan con un corpus mucho más extenso que en América Latina y una tradición de más largo recorrido. El campo de los Presidential Studies, donde normalmente se enmarca el análisis de la vicepresidencia, lleva varias décadas haciendo lo que los latinoamericanistas han comenzado a hacer mucho más recientemente; pero tampoco allí se han ocupado de debatir los fundamentos filosóficos de la vicepresidencia. Tampoco se han acabado de sentar las bases de determinados principios vinculados a la vicepresidencia que exceden los límites de este artículo, pero que indudablemente deben ser puestos en cuestión en trabajos complementarios; por ejemplo, si el vicepresidente pertenece al Poder Ejecutivo, al Legislativo (en

La bibliografía en este ámbito es tan exigua que prácticamente se puede citar el corpus completo: M. Serrafero, El poder y su sombra. Los vicepresidentes, Buenos Aires, Editorial de Belgrano, 1999; "Hacia una nueva vicepresidencia. Reflexiones desde el caso norteamericano", Revista de Derecho Político 88, 2013, pp. 367-392; "La Vicepresidencia y las coaliciones políticas: el caso de Argentina", Revista de Sociologia e Politica 65, pp. 15-38; A. Sribman Mittelman, "La Vicepresidencia Argentina (1983-2009)", Cadernos de Estudos Latino-Americanos 10; La sucesión del poder. Una aproximación general desde experiencias de los siglos XX y XXI, Salamanca, Ediciones Universidad; "La vicepresidencia en América Latina: un mal innecesario", América Latina Hoy 81, pp. 51-75; "La vicepresidencia en México: un debate pendiente", Revista Estudios Politicos 48, pp. 73-94; P. Mieres, "Las candidaturas vicepresidenciales en las campañas electorales. El caso de Uruguay 2009", ponencia presentada en el Cuarto Congreso de Ciencia Política de Uruguay; P. Mieres y E. Pampín, "La trayectoria de los vicepresidentes en los regímenes presidencialistas de América", Revista de Estudios Politicos 167, pp. 99-132; G. Bidegain, "Vicepresidentes en América del Sur: una agenda de investigación", Colombia Internacional 89, pp. 159-188; L. Marsteintredet, "La vicepresidencia y los problemas de la sucesión presidencial en América Latina. Viejos y nuevos retos para el presidencialismo", Política y Gobierno XXVI (1), pp. 117-137; L. Marsteintredet y F. Uggla, "Allies and Traitors: Vice-Presidents in Latin America", Journal of Latin American Studies, pp. 1-28, DOI: 10.1017/S0022216X18001098; A. Pignataro y M. Taylor-Robinson, "Party competition, gender quotas, and enhanced inclusiveness in the selection of vice-presidential candidates", Politics, Groups, and Identities, DOI: 10.1080/21565503.2019.1637354; y F. Uggla, "The politics of vice-presidential selection in Latin America", Electoral Studies 65, DOI: 10.1016/j.electstud.2020.102154. los casos en que es presidente nato del Senado) o a ambos; o si al asumir la presidencia recibe el título de presidente o solamente las funciones. La lista de principios pendientes de definir es verdaderamente extensa.

Aquí se analizarán dos de ellos: el de inmediatez y el de disponibilidad, a la luz de antecedentes empíricos muy anteriores a la vicepresidencia latinoamericana. Aunque con el desarrollo de este artículo se irá desvelando en mayor detalle la naturaleza de estos principios, se puede comenzar aquí con una definición mínima de cada uno: el de inmediatez se refiere a la búsqueda de que entre la salida de un gobernante y la entrada de su sucesor transcurra el menor tiempo posible; el de disponibilidad remite a la mayor o menor capacidad del gobernante para dirigir su propia sucesión de acuerdo a sus deseos e intereses.

La relevancia de esta investigación radica en que estos principios, que podrían parecer incuestionables, han sido puestos en duda en la práctica en innumerables ocasiones; por lo tanto, es necesario diseccionarlos y comprender las potencialidades y las consecuencias de su vigencia en el caso de la vicepresidencia en América Latina. En efecto, a lo largo de la historia estos dos principios se han aplicado o rechazado en los más diversos sistemas políticos. Y la posibilidad de aplicarlos -o no- ha generado interesantes debates en el ámbito de la filosofía política. Así ha ocurrido también en el caso de la sucesión en América Latina. Prácticamente desde el propio tiempo de la independencia, a comienzos del siglo XIX, han aparecido proyectos políticos en los que la inmediatez y la disponibilidad del Ejecutivo (extrapolación republicana de la disponibilidad de la Corona) eran tratados de diversas maneras.

Por otro lado, el recurso a la filosofía política de la Francia tardomedieval resulta fundamental porque propone una reflexión sobre la sucesión del poder que desborda lo estrictamente funcional, lo pragmático, y procura abordar ciertos debates a partir de principios más generales, dando a las figuras jurídico-políticas en estudio un fundamento mucho más sólido.

La tesis de este trabajo es que los principios de disponibilidad y de inmediatez se pueden proyectar sobre la vicepresidencia desde su origen vinculado a la monarquía, y permiten dotar a este cargo de un fundamento teórico hasta ahora faltante.

\section{La literatura teórica sobre la vicepresidencia}

El presidencialismo, el Ejecutivo unipersonal y la vicepresidencia fueron creaciones de los Padres Fundadores estadounidenses ${ }^{3}$. Como en el caso de la práctica totalidad de las instituciones políticas de la historia, cabría esperar que apareciera en torno a estos nuevos cargos una serie más o menos extensa de aportaciones teóricas, ya desgranándolos, ya justificándolos, ya denostándolos.

La vicepresidencia en el marco de un Ejecutivo presidencialista unipersonal lleva más de dos siglos huérfana de teoría. Lo más parecido que se ha desarrollado es

A. Demicheli, Formación constitucional rioplatense, Montevideo, Barreiro y Ramos, 1955. 
el debate constituyente, que en el caso estadounidense fue verdaderamente pobre -a este respecto-, y en gran parte de América Latina lo fue más aún.

Durante estas dos centurias, los países latinoamericanos han reformado una y otra vez sus constituciones. En una parte muy considerable de los casos, estos cambios incluyeron el paso de un mecanismo sucesorio a otro ${ }^{4}$. Por ejemplo, la incorporación del vicepresidente cuando no lo había o su eliminación cuando lo había. Sin embargo, la carencia de un desarrollo teórico a este respecto determinó que todas esas modificaciones se hicieran o bien en respuesta a situaciones concretas, con los sesgos cortoplacistas que ello impone, o bien -más grave aún- sin motivación alguna ${ }^{5}$.

Ello explica, asimismo, la ausencia casi total de reflexiones teóricas, de debates, de pensamiento político acerca de la sucesión en general y la vicepresidencia en particular. Como se ha indicado anteriormente, los dos escenarios habituales a lo largo de la historia constitucional latinoamericana han sido, por una parte, la imitación indeliberada de textos constitucionales extranje$\operatorname{ros}^{6}$; por otra, la alteración de la figura sucesoria como respuesta inmediata a circunstancias políticas concretas, primando el interés inmediato de quien promovía la reforma y quedando al margen cualquier debate extenso y sostenido en principios. Ello queda reflejado tanto en fuentes primarias (actas de los congresos constituyentes) como secundarias (estudios exhaustivos sobre la evolución constitucional de los diversos países, como los referidos en la n. 3 ).

Lo anterior tiene graves consecuencias tanto en el ámbito práctico como en el teórico. En cuanto al práctico, Sribman Mittelman ${ }^{7}$ da cuenta de la alta frecuencia con que la vicepresidencia es origen de inestabilidad política. Respecto del teórico, es patente la falta de unos principios que expliquen la adopción de un mecanismo sucesorio u otro, que establezcan prioridades en relación a las funciones que debe cumplir la figura sucesoria, que expliquen el carácter secundario de sus defectos en razón del carácter primario de sus virtudes.

Aclaremos lo anterior con un ejemplo y una analogía. En primer lugar, el ejemplo. Michel Temer accedió a la presidencia de Brasil al caer la titular, Dilma Rousseff, como consecuencia de un juicio político en su contra. Temer, acusado de conspirar para que se ac-

4 La lista de ejemplos es ingente. Para referir apenas algunos, Cf. L. Mariñas Otero, Las Constituciones de Guatemala, Madrid, Instituto de Estudios Políticos, 1958; J. Pareja Paz-Soldán, Las Constituciones del Perú, Madrid, Cultura Hispánica, 1954; R. Borja y Borja, Las Constituciones del Ecuador, Madrid, Cultura Hispánica, 1951; C. F. Trigo, Las Constituciones de Bolivia, Madrid, Instituto de Estudios Políticos, 1958.

La Constitución argentina de 1853 es claro ejemplo de esto: tras cuatro décadas y media de Ejecutivo sin vicepresidente, la carta magna de ese año incorporó esta figura sin mediar debate alguno, copiándola de la Constitución estadounidense.

6 Cf. a modo de ejemplo la siguiente afirmación de A. Uribe Vargas, Las constituciones de Colombia, Madrid, Ediciones Cultura Hispánica, 1985, p. 61: "Después del grito emancipador, lo cierto es que hemos alternado en influencias e intentos de transplante institucional, sin que pueda decirse, hasta nuestros días, que el país se ha liberado definitivamente de la manía de copiar constituciones o de injertarlas".

A. Sribman Mittelman, La vicepresidencia en América Latina: un mal innecesario, op. cit. tivara dicho proceso judicial, llegó al poder con niveles de legitimidad insólitamente bajos. Se podría afirmar, entonces, que el formato de vicepresidente fijo, elegido junto al presidente, consagra el principio de inmediatez en desmedro del de legitimidad. Esto es que facilita la asunción del presidente reemplazante de manera inmediata tras la vacancia del titular, pero no ofrece garantía alguna de que el nuevo mandatario goce de legitimidad. Si se considera que la inmediatez sucesoria es principio irrenunciable y prioritario, la falta de legitimidad del vicepresidente se asumirá como un mal menor. $\mathrm{Si}$, por el contrario, la legitimidad es primordial, será necesario modificar el mecanismo sucesorio del Ejecutivo brasileño. Lo que en ningún caso resulta concebible es que rijan instituciones que no tengan un sustento teórico, que no se justifiquen en una elección de principios.

En segundo lugar, la analogía. En el nacimiento del presidencialismo -en los Estados Unidos de finales del siglo XVIII- aparecieron en pugna dos principios: por un lado, el de eficacia, que perseguía la constitución de un Ejecutivo fuerte, con capacidad de decisión rápida, no sometido a debates infinitos que paralizaran la acción del gobierno. Por otro lado, el de limitación del poder: la búsqueda de ahuyentar el fantasma del absolutismo monárquico hacía temer la concentración del Ejecutivo en un solo ciudadano ${ }^{8}$. Los Estados Unidos se decantaron finalmente por el modelo unipersonal. Es decir, se impuso el principio de eficacia. Si algún presidente hubiera cometido abusos que pusieran este diseño en tela de juicio, se habrían abierto dos opciones igualmente consistentes: o bien sostener que el principio de eficacia seguía siendo primordial, y que por tanto los mencionados abusos debían ser tolerados en pos de ese principio superior; o bien modificar el orden de principios, dejando asentado que el de desconcentración del poder es prioritario, y que evitar cualquier abuso de poder ha de situarse por encima y por delante de la eficacia. En cualquiera de los dos casos, la existencia de tales principios habría permitido un debate de ideas robusto. Por el contrario, resultaría azaroso, tanto a nivel teórico como en sus consecuencias prácticas, intentar resolver este dilema sin poder recurrir a principio alguno, simplemente buscando paliar los conflictos a corto plazo, cambiando de modelo Ejecutivo una y otra vez en respuesta a circunstancias puntuales.

Tal elección de principios implica, por supuesto, una toma de decisiones. Como en toda construcción política, se ha de renunciar a unos principios para apuntalar otros. Al abordar la vicepresidencia, ¿qué principios se desea priorizar? ¿Es más importante la inmediatez de la sucesión o la legitimidad del sucesor? ¿Es aplicable el principio elegido en la pregunta anterior tanto a tiempos de paz como a tiempos de guerra? ¿Qué consecuencias teóricas y prácticas tiene la disponibilidad, es decir, la capacidad del presidente para remover a su vice y nombrar uno nuevo?

Sorprendentemente, estas preguntas no han sido abordadas de una manera reflexiva, extensa y profunda por pensador político alguno. Si bien se trata de cuestio-

\footnotetext{
A. Demicheli, op. cit
} 
nes que resulta imposible tratar suficientemente en un solo artículo, se propone aquí una primera aproximación a dos de esos principios.

\section{Los principios de disponibilidad e inmediatez en los albores de la Edad Moderna}

\subsection{La disponibilidad de la corona}

Hacia 1418, Francia se encuentra dividida entre la casa de Orleans, a la que pertenece el delfín, y el duque de Borgoña, cuyos partidarios se alían con Inglaterra mediante el tratado de Troyes (1420). Este documento establecía, en contra de los usos históricos, que el rey podía regular su propia sucesión como quisiera, poder que sus predecesores jamás habían tenido.

En el marco de este enfrentamiento aparecerán importantes teorías, defendidas por juristas favorables a uno y otro bando. Los partidarios de la causa real y los derechos del delfín sostenían vigorosamente que el monarca reinante, no importaba quién fuera, no podía en ningún caso disponer libremente de la corona en detrimento del heredero al trono que designara la costumbre.

A la cabeza de este movimiento se encontraba el jurista languedoquiano Jean de Terrevermeille, que intenta demostrar los derechos incontestables del delfín. Para esto afirma, en primer lugar, que todas las reglas sucesorias que han regido hasta entonces son de naturaleza consuetudinaria. Esas costumbres, elaboradas lentamente por la comunidad política en conjunto, constituyen un orden jurídico independiente y superior. La suma de exigencias, creencias y prácticas hasta entonces en vigor han dado forma a un conjunto objetivo que escapa tanto a la voluntad del cuerpo político como al deseo de los príncipes. Las reglas que rigen la sucesión real se encuentran fuera del campo del Derecho común. Por otro lado, la sucesión real no tiene nada que ver con la sucesión privada, en la que el testador puede decidir quién debe heredar sus bienes y quién queda desheredado, y en la que un heredero designado tiene derecho a rechazar su parte de la sucesión.

La sucesión real no es hereditaria ni patrimonial; pertenece a una categoría que Terrevermeille llama "casi hereditaria", en tanto la corona sólo revierte sobre el hijo mayor del rey o, en su ausencia, sobre el varón colateral más próximo.

Según este autor, el rey no puede disponer de los bienes reales ni legarlos a su sucesor, sino simplemente dejar que las leyes consuetudinarias actúen. Tampoco puede descartar a su sucesor. Puesto que todo este entramado legal está destinado a asegurar la continuidad de la función real, Terrevermeille habla de "heredero necesario". El jurista intenta demostrar que el delfín es una especie de co-administrador: en virtud del jus filiationis que lo liga a su padre, goza de ciertos derechos y privilegios propios de su familia. Siguiendo a Aristóteles, Terrevermeille plantea la identidad entre el padre y el hijo, esencial para justificar la transmisión del poder al primogénito. El delfín posee pleno derecho de asegurar el gobierno y la administración del reino en su condición de regente toda vez que su padre se encuentre impedido.

Además de Terrevermeille aparecieron durante la primera mitad del siglo XV numerosos escritores favorables al delfín y al principio de inmediatez, y contrarios al de disponibilidad. En 1445 se da un paso decisivo en este sentido cuando Jean Juvénal des Ursins, defensor de la causa real y de la legitimidad de Carlos vII, escribe que el rey no puede eliminar de la sucesión a su heredero ni alienar o transmitir el reino a otra mano que la señalada por la sucesión hereditaria; y si tuviera un hijo, no puede desheredarlo ni evitar que posea el reino después de su propio reinado.

La literatura en defensa del delfín contenía asimismo un verdadero sentimiento nacional y una profunda lealtad monárquica que favorecían el desarrollo de una sólida resistencia hacia el extranjero. En este movimiento se inscribe la Complainte des bons Français (1420) del normando Robert Blondel; la Quadrilogue invectif y la Lettre à l'université de Paris, de Alain Chartier (1422); y la anónima Réponse d'un bon et loyal Français au peuple de France de tous états (Guillot, Rigaudiere y Sassier, 1994).

Hacer al delfín heredero necesario le aseguraba la sucesión a la corona. Pero para que el principio fuera eficaz aún hacía falta que, una vez abierta, la sucesión se regulara con la mayor velocidad posible y que no se creara ruptura alguna en el ejercicio del poder. De esa continuidad dependía también la del Estado.

\subsection{La inmediatez}

El principio de inmediatez, esto es, que el intervalo entre la muerte del rey y el establecimiento de su sucesor fuera el menor posible, tenía bases doctrinales, jurídicas, prácticas y consuetudinarias.

En cuanto a las primeras, durante el siglo XII tiene gran difusión la teoría de los dos cuerpos de Cristo, que es adaptada por el pensamiento político a la organización de los reinos9. Al corpus verum Christi corresponde el corpus naturale regis, es decir, el cuerpo físico, natural y mortal del rey; mientras que al corpus mysticum de Cristo corresponde el Estado y, por extensión, las funciones que éste ejerce. Este movimiento doctrinal tendrá su mayor expansión en la Inglaterra de los Tudor, aunque también fue incorporado por los pensadores franceses de la Baja Edad Media.

La teoría partía de la decretal Quoniam abbas del papa Alejandro III (siglo XII), en la que el Sumo Pontífice reconocía innecesario delegar la responsabilidad de la abadía sobre cada nuevo abad, sino que tal delegación había sido realizada de una vez por todas a la función, a la dignitas, que dura mientras sea ocupada por sucesivos titulares. A partir de esta idea, los canonistas del siglo XIII concluirán que, en tanto los individuos mueren diariamente, la dignitas no muere jamás.

Así, el concepto de dignitas aportaba al corpus mysticum una característica decisiva: la perpetuidad. Es de-

La evolución de las teorías de los dos cuerpos es magistralmente abordada por E. Kantorowicz, Los dos cuerpos del rey, Madrid, Akal, 2012. 
cir que la realeza trasciende a la persona física de sus titulares.

Además, la dignitas será utilizada para justificar la exclusión de la mujer de la corona: François de Meyronnes expone en 1322 que aquélla puede tomar parte en una herencia privada, pero en ningún caso cuando una dignitas está en juego. Jean de Terrevermeille, tomando la despersonalización de esa dignidad perpetua, señala al rey como un simple "administrador" de aquélla; y para que esta función administrativa se cumpla, todo debe estar preparado para una sucesión inmediata cada vez que desaparece el cuerpo natural del soberano.

La doctrina confluyó en la defensa del delfín con otros tres elementos. En primer lugar, la costumbre: la noción de los dos cuerpos del rey, que fue asentada por los autores citados, se había ido incubando en el pensamiento europeo durante los siglos anteriores. En Francia, una muestra de ello es la extendida presencia del adagio "le mort saisit le vif", en donde aparecía la idea de continuidad entre el muerto y su sucesor.

En segundo lugar, la legislación: entre 1374 y 1407 se promulgan varias leyes vinculadas a la sucesión. La primera de ellas rebaja la edad de acceso al trono a trece años; lo que se buscaba con esto era que, en caso de minoría de edad del rey, la regencia fuera lo más breve posible, de modo que el regente no acabara haciéndose con el poder.

En 1403 se da un paso más, eliminando la regencia por completo para garantizar la instantaneidad de la sucesión. Se prevé que el heredero sea rey sin importar la edad que tenga y sin necesidad de consagración, y que se prohíba toda clase de regencia. Si el nuevo rey es demasiado joven, la administración queda provisoriamente en manos de un concejo de tutela encabezado por la reina, asistida por príncipes de sangre real. Lo anterior conlleva que resulte inútil establecer con cuántos años el rey pasa a ser mayor de edad. La última ordenanza, de 1407, que venía a reforzar la de 1403, estipulaba que tan pronto como muere el rey, aquel de sus hijos llamado a sucederlo se encuentra inmediatamente investido de la auctoritas regia. Todos estos esfuerzos no obstaban para que se mantuviera una considerable brecha entre la ley y la práctica.

La práctica es precisamente el tercer elemento que confluye con la doctrina. Ya en el siglo XIV los presidentes del Parlamento no vestían duelo en los funerales del rey, sino su vestimenta oficial. Con esto transformaban los funerales reales en un símbolo de la continuidad del Estado, más allá de la muerte del cuerpo físico del rey. Esta práctica contribuyó a fijar la idea de que, tanto por la identidad de naturaleza existente entre el padre y el hijo como en razón de la dignitas perpetua que ambos encarnan, el hijo debe suceder inmediatamente al rey difunto. La continuidad de la función no podía disociarse de una continuidad física. En los funerales aparece, además, una segunda práctica que tendrá gran influencia sobre los asuntos sucesorios: la aparición de la efigie del rey vivo junto al cuerpo del rey muerto.

Por último, el elemento consuetudinario: la proclamación y las ceremonias en honor al nuevo rey comienzan a tener lugar antes de los funerales del monarca an- terior. Poco a poco se va reduciendo el tiempo entre la muerte de un rey y la coronación del siguiente, hasta que se fija la práctica según la cual en el propio entierro del rey se produce la proclamación de su sucesor. A partir de entonces se hará todo lo posible para explicar la continuidad del poder real independientemente de la muerte de su titular.

\section{Entre la Edad Media y las independencias americanas: la filosofía política moderna}

Los dos conceptos de que se ocupa este trabajo se desarrollan, como acaba de verse, a caballo entre la Baja Edad Media y el comienzo de la Edad Moderna. Esta última será testigo de una expansión notable de la producción teórica sobre el poder. Con el nacimiento del Estado moderno aparecen muchos grandes nombres del pensamiento político que continúan proporcionándonos muchas de las bases teóricas del poder en la actualidad.

Una discusión exhaustiva del tratamiento que se dio a estos conceptos durante la Edad Moderna excede los límites de este trabajo. No obstante, resulta necesario hacer una breve referencia a algunos pensadores de este período para dar cuenta del tránsito de la Francia tardomedieval a las independencias latinoamericanas. No hacerlo supondría desarraigar el pensamiento de los fundadores de las nuevas repúblicas latinoamericanas, desconectarlos de sus fuentes más inmediatas ${ }^{10}$.

El concepto de inmediatez aparece mayoritariamente cuando se abordan los peligros del interregno, cuasi sinónimo de acefalía y anarquía. Esta circunstancia, a su vez, suele presentarse por dos vías: para quienes abogan por la sucesión hereditaria, el interregno es consecuencia de la demora en elegir nuevo monarca, demora inherente a la lentitud del proceso electivo. Para quienes apoyan la monarquía electiva, el interregno viene adjunto a diversas coyunturas en que no existe un sucesor hábil para el príncipe saliente: bien el heredero es menor de edad, bien no hay tal heredero, bien hay varios descendientes del príncipe que se disputan el reino, entre otras posibilidades.

En cuanto a la disponibilidad del poder, el debate se presenta mayoritariamente declinado en términos de monarquía electiva frente a monarquía hereditaria. Ambos sistemas pueden conjugarse con disponibilidad o indisponibilidad: en el caso de la monarquía electiva, la elección puede estar en manos del rey saliente o de otros agentes (príncipes electores, corte, etc.); en la primera opción hablaríamos de disponibilidad de la corona. En el caso de la monarquía hereditaria, algunos teóricos se pronuncian a favor de que el rey elija a su heredero de entre los de su linaje, mientras que otros abogan por la

\footnotetext{
10 La bibliografía sobre las influencias intelectuales sobre los padres de las patrias latinoamericanas es sobremanera extensa. Solamente a modo de ejemplo cf. R. Zapata, Libros que leyó el Libertador Simón Bolivar, Santafé de Bogotá, Instituto Caro y Cuervo, 1997; E. Gandía, San Martín. Su pensamiento político, Buenos Aires, Pleamar, 1964; M. C. Yerga de Ysaguirre, "Los fundamentos filosóficos de las ideas económicas de Manuel Belgrano (1770-1820)", Revista de la Facultad de Ciencias Económicas 121, 2000, pp. 121-136.
} 
sucesión incontestable del primogénito; nuevamente, la primera opción sería un ejemplo de disponibilidad.

En todo caso, no todos los filósofos políticos que aparecen entre Maquiavelo y la Revolución Francesa dejan asentada su posición a este respecto. En algunos de ellos se puede apenas leer una tendencia entre líneas, y en otros ni siquiera eso. Unos pocos, por el contrario, hacen referencia clara a la disponibilidad del poder. A continuación se presentan algunos ejemplos de esta diversidad de tesis. Con ello, insistimos, no se pretende hacer un relevamiento exhaustivo de los argumentos sobre este asunto a lo largo de tres siglos; se trata apenas de ilustrar las distintas posiciones recurriendo a algunos de los pensadores más representativos del período.

Jean Bodin es partidario de la sucesión hereditaria y se declara contrario a cualquier alteración del orden de primogenitura. Pero ante todo, denuesta la monarquía electiva; con tal de no caer en ella prefiere aceptar la disponibilidad de la corona ${ }^{11}$. En estilo opuesto, Maquiavelo es partidario de la monarquía electiva; y con tal de que esta no tenga lugar, apoya la adopción, que es una forma de disponibilidad de la corona ${ }^{12}$.

Juan de Mariana rechaza no solamente la disponibilidad de la corona en general, sino incluso el derecho del rey a cambiar el orden sucesorio entre sus hijos ${ }^{13}$. Opuestamente, el ejemplo más explícito de defensa de la disponibilidad de la corona es el de Thomas Hobbes, quien afirma que el pueblo soberano puede traspasar su soberanía a un solo hombre nombrado y aprobado por mayoría de votos ${ }^{14}$.

En algunos casos, como el de Robert Filmer, no se propone expresamente una tesis a este respecto, pero es posible interpretar una oposición implícita a la disponibilidad de la corona. Al preguntarse por cómo se debe actuar en caso de que la corona caduque por falta de heredero no plantea la posibilidad de que el rey elija a su sucesor; sostiene, en cambio, que el poder vuelve a los príncipes y jefes de familias independientes, que eligen al nuevo monarca ${ }^{15}$.

Spinoza, por su parte, se opone a la disponibilidad de la corona de manera explícita: "Quienes sostienen que el rey, por ser señor del Estado y poseerlo con derecho absoluto, puede entregarlo a quien quiera y elegir por sucesor a quien quiera, y que, por consiguiente, el hijo del rey es por derecho heredero del Estado, están claramente equivocados"16. En este mismo sentido se manifiesta Diderot cuando afirma que el "portador de la corona puede desembarazarse completamente de ella si tal es su voluntad, pero no puede colocarla en la cabeza

11 J. Bodin, Los seis libros de la república, Madrid, Tecnos, 1985, pp. 292-296.

12 N. Maquiavelo, Discursos sobre la primera década de Tito Livio, Madrid, Alianza, 2000, p. 65.

13 J. de Mariana, La dignidad real y la educación del rey, Madrid, Centro de Estudios Constitucionales, 1981, pp. 41-55.

14 T. Hobbes, Elementos de Derecho Natural y Político, Madrid, Centro de Estudios Constitucionales, 1979, pp. 274-275.

15 R. Filmer, Patriarcha o El poder natural de los Reyes, Madrid, Espasa, 1920, pp. 20-22.

16 B. Spinoza, Tratado político, Madrid, Alianza, 1986, pp. 156-157. de otro sin el consentimiento de la nación, que la ha colocado en la suya" $"$.

Se puede observar en los ejemplos anteriores que los argumentos a favor de una postura u otra son muy diversos: desde el mandamiento divino hasta el máximo pragmatismo político. Ello hace que en muchos casos resulte imposible el diálogo: ¿cómo poner en oposición la palabra bíblica, por un lado, y la búsqueda terrenal de estabilidad política, por otro? Evidentemente se trata de argumentos que se mueven en planos paralelos. En todo caso se puede afirmar que todos ellos procuran justificar la soberanía de un principio: la estabilidad, el cumplimiento del mandato divino, la cohesión política... y al tiempo que lo hacen, admiten implícitamente la postergación de los otros. Esa elaboración de principios es precisamente la tarea pendiente acerca de la vicepresidencia.

\section{Los principios del presidencialismo: indisponibilidad e inmediatez}

Como se ha afirmado al comienzo de este trabajo, el proceso de constitución de los Estados Unidos como cuerpo político recibió mayor impulso de ciertos objetivos prácticos que de bases y debates teóricos. No obstante, diversas fuentes permiten afirmar retrospectivamente que la presidencia nace en ese país sustentada en los principios de no disponibilidad (o indisponibilidad) e inmediatez; o, más exactamente, en la extrapolación republicana de tales principios, originariamente asociados a regímenes monárquicos.

La indisponibilidad consistía en que el presidente tuviera un mandato limitado en el tiempo y que, en frontal rechazo del precedente monárquico británico, ni fuera sucedido mediante herencia dinástica ni pudiera elegir a quien lo reemplazara ${ }^{18}$. Es decir, el presidente estadounidense no disponía del Ejecutivo en el sentido en que algunos monarcas europeos disponían de su corona. Tal condición se vería ligeramente modificada por la XXV Enmienda constitucional, de 1967. Esta determina que, ante la vacancia de la vicepresidencia, el presidente puede designar un nuevo vice, de manera que la sucesión nunca quede huera. En todo caso, el presente artículo se centra en América Latina, en donde ningún país incorporó tal previsión. El que más se acerca es Ecuador; allí, si la vicepresidencia queda vacante, el presidente elabora una terna de candidatos para llenar el puesto y la presenta a la Asamblea, que escoge a uno de los tres nominados. En todo caso, si la disponibilidad del Ejecutivo en el caso de Estados Unidos se presenta ya muy atenuada y como mecanismo excepcional, en Ecuador, en virtud del sistema de terna, lo es mucho más aún. De manera que se puede hablar de indisponibilidad del Ejecutivo en todos los países latinoamericanos que cuentan con vicepresidencia.

Lo anterior conoció una única pero insigne excepción: el Discurso de Simón Bolívar al Congreso Consti-

D. Diderot, Escritos políticos, Madrid, Centro de Estudios Constitucionales, 1989 , pp. 7-8.

18 A. Demicheli, op cit. 
tuyente de Bolivia, de 1826. Allí, el Libertador justifica algunas de las instituciones adoptadas en su proyecto constitucional boliviano. Entre otras, propone la instauración de una presidencia vitalicia con un vicepresidente hereditario, escogido por el presidente. El principio de disponibilidad alcanza su máximo esplendor:

El Presidente de la República nombra al Vice-Presidente para que administre el Estado y le suceda en el mando. Por esta providencia se evitan las elecciones, que producen el grande azote de las repúblicas, la anarquía, que es el lujo de la tiranía y el peligro más inmediato y más terrible de los gobiernos populares. Ved de qué modo sucede como en los reinos legítimos la tremenda crisis de las repúblicas ${ }^{19}$.

Es necesario apuntar, aunque no se tratará detalladamente en este artículo, que a continuación señala Bolívar otros dos principios que son fundamento de su propuesta constitucional: la estabilidad y la unidad. Resulta evidente que la sucesión del poder está íntimamente vinculada a la estabilidad y, por vía de esta, a la unidad $^{20}$. Se afirmaba al comienzo de este texto que la adopción de unos principios implica la renuncia a -o la postergación de- otros. En este sentido resulta evidente que el principio democrático, al menos como se entiende la democracia actualmente, queda relegado a un segundo plano, precisamente en favor de la estabilidad y la unidad. Si bien afirma Bolívar que ha tomado como modelo "el Ejecutivo de la República más democrática del mundo" 21 , en referencia a Haití, es claro que tal afirmación se basa en una concepción de la democracia muy distante de la que manejamos en la actualidad, y que es categóricamente incompatible con una presidencia vitalicia y una vicepresidencia hereditaria. Por estos mismos motivos cabe conjeturar que el proyecto bolivariano postergaba el principio de legitimidad.

Respecto de la inmediatez, el Ejecutivo unipersonal estadounidense -luego adoptado por los nuevos Estados latinoamericanos- fue concebido en atención a principios íntimamente relacionados con aquel. El paso del gobierno en manos del Congreso -desde 1781 hasta $1787^{22}$ - a la concentración del poder en un individuo independiente del Legislativo derivaba precisamente de la necesidad de garantizar un mando concentrado que respondiera con inmediatez a las necesidades del estado de guerra en particular, y del nuevo -y aún frágil- Estado en general.

En sentido contrario, el origen de la vicepresidencia estadounidense permite afirmar que la inmediatez no fue el motivo de incorporar dicho cargo al entramado constitucional. En efecto, este cargo no nació como dispositivo para garantizar una sucesión inmediata del presidente, sino como efecto colateral de la búsqueda de solución a una grieta del sistema electoral ${ }^{23}$. Si acaso el

19 S. Bolívar, "Discurso del Libertador al Congreso Constituyente de Bolivia", Pensamiento Constitucional 2, 1995, p. 239.

20 “(...) la monarquía que gobierna la tierra ha obtenido sus títulos de aprobación de la herencia que la hace estable, y de la unidad que la hace fuerte" (S. Bolívar, op. cit., p. 239).

21 S. Bolívar, ibidem, p. 237.

22 Cf. A. Demicheli, op . cit., vol. 2, p. 292.

23 Pueden consultarse los detalles en A. Sribman Mittelman, La sucesión del poder, op. cit. diseño adoptado favorece aquel principio, se puede considerar en origen un efecto secundario. Pero solamente en origen: esto cambiaría con la mencionada Enmienda de 1967, específicamente orientada a la inmediatez. En plena Guerra Fría, y frente a las deficiencias sucesorias preexistentes, se hacía acuciante la necesidad de proveer "una presidencia plenamente funcional en todo momento"24. Es decir, de garantizar una sucesión inmediata.

En el caso de la vicepresidencia en América Latina, habiéndose copiado en gran parte de la región el modelo norteamericano, vale decir lo mismo: que no hay una fundamentación teórica en origen, previa a la incorporación de la vicepresidencia a las constituciones. En algunos casos la hay a posteriori; en otros, ni siquiera eso.

\section{La vicepresidencia en América Latina}

Al hablar del Ejecutivo unipersonal ya se han adelantado algunas pinceladas sobre la inmediatez y la disponibilidad en la sucesión del poder. Queda hacer algunas reflexiones sobre el caso específico de la vicepresidencia y sobre algunos de los perfiles concretos que este cargo ha adquirido en distintos países latinoamericanos.

Comencemos por retomar una clasificación de la vicepresidencia establecida por Sribman Mittelman ${ }^{25}$. Allí se habla de una vicepresidencia rígida cuando el presidente no puede remover al vice ni nombrar a uno nuevo en caso de vacancia del titular; semielástica en casos como el de Ecuador, donde el presidente no puede expulsar al vice pero puede participar en la nominación de uno nuevo si el titular falta; y elástica, allí donde el presidente puede remover al vice y designar a su reemplazante. Es evidente que esta categorización está íntimamente unida al principio de disponibilidad. Un mayor grado de esta se corresponde con una vicepresidencia elástica, mientras que un menor grado la hace tender al extremo rígido del continuum.

Esta categorización contemporánea, así como su correspondencia con los principios más antiguos aquí estudiados, tienen aplicaciones de máxima importancia en el desempeño de los Ejecutivos latinoamericanos. Gran parte de los conflictos tocantes a los vicepresidentes que se han dado durante las últimas décadas habrían sido evitables de contar este cargo con un carácter elástico; o, dicho de otra manera, de no encontrarse la presidencia en casi toda América Latina atada por el grado máximo de indisponibilidad.

El pasado reciente latinoamericano, desde el retorno de gran parte de la región a la democracia en la década de 1980, ha sido testigo de vicepresidentes que -presuntamente- conspiran para hacer caer al presidente; que, sin intentar hacerlo caer, hacen oposición desde dentro del Ejecutivo; que se ven implicados en escándalos de corrupción, salpicando al Ejecutivo en su conjunto; que

\footnotetext{
Constitution Center. "Amendment xxv. Presidential Disability and Succession", disponible en https://constitutioncenter.org/interactiveconstitution/amendments/amendment-xxv.

25 A. Sribman Mittelman, La vicepresidencia en América Latina: un mal innecesario, op. cit.
} 
renuncian, dejando la vicepresidencia vacía y el Ejecutivo debilitado; que despiertan un fuerte rechazo de sectores clave, como el ejército nacional, y por tanto se ven impedidos de asumir la presidencia cuando el titular la deja vacante ${ }^{26}$. En todos estos casos, el principio de disponibilidad -aplicado en el grado oportuno- permitiría al presidente apartar al vice de su cargo y desactivar tales conflictos.

Naturalmente, al mismo tiempo le daría al primer mandatario una capacidad de manipular su entorno institucional que podría ser evaluada como excesiva. Pero no se trata aquí de juzgar la conveniencia o los perjuicios derivados del diseño actual, sino de echar luz sobre la existencia de estos principios y sobre la necesidad de desarrollar una reflexión teórica que justifique su conservación o conduzca a su reemplazo. Se trata de fomentar un debate que permita definir qué principios prioriza cada sistema político: bien la disponibilidad, bien la limitación del poder presidencial.

De acuerdo con lo anterior, se ha de plantear qué ocurriría si se implantara el principio de disponibilidad en el presidencialismo latinoamericano ${ }^{27}$. Esto se podría producir en diversos grados. La riqueza de la arquitectura política permite concebir numerosas combinaciones, pero aquí se considerarán solo los cuatro grados básicos: primero, la capacitación del presidente para apartar al vice pero no para nombrar otro; segundo, la capacidad de desplazar al vice y nombrar sustituto de manera directa; tercero, la imposibilidad de remover al vice, pero la habilitación para proponer al Legislativo una terna para su reemplazo en caso de quedar la vicepresidencia vacante (el modelo ecuatoriano); cuarto, la incapacidad de apartar al vice pero la posibilidad de nombrar vice directamente -sin dispositivo de terna ni intervención del Legislativo- si este cargo queda vacante (como ocurre en Estados Unidos en virtud de la Xxv Enmienda).

A su vez, cada uno de los casos anteriores puede ser declinado de dos maneras: al quedar vacante la vicepresidencia, $i$ es obligatorio que el presidente nombre otro vice o es optativo? Las consecuencias de tomar una opción o la otra son de gran envergadura, tanto en términos teóricos como prácticos. Ya se ha dicho que aquí no nos ocuparemos de los segundos. En cuanto a los primeros, el carácter obligatorio de la sustitución supone respaldar unos principios, mientras que el carácter opcional implica priorizar otros. En este punto, cada uno de los principios aquí tratados funciona como contrapeso del otro: si el nombramiento de un nuevo vice es obligatorio, la inmediatez queda por delante de la disponibilidad, en tanto se fuerza al presidente a contar con un reemplazo inmediato en desmedro de su discrecionalidad para optar eventualmente por prescindir de un vice; si, en cambio, tal designación es opcional, la disponibilidad prima frente a la inmediatez, en la medida en que se ofrece al presidente la posibilidad de continuar sin vice, si así lo desea, a costa de garantizar una sucesión inmediata.

\footnotetext{
Ibidem para una relación de los mismos.

27 Naturalmente, la pregunta apunta a qué ocurriría en términos teóri$\cos$, de principios. Intentar predecir qué ocurriría en términos prácticos, en la política real, es cuestión especulativa que no tiene cabida en el ámbito de la investigación científica.
}

En todo caso, volvamos atrás y comencemos por el primero de los cuatro grados mencionados. Si el Presidente adquiere derecho a remover al vice pero no a investir a otro, la disponibilidad choca con el principio de inmediatez. Es decir, si el presidente aparta al vice pero no puede nombrarle sustituto, de modo que este cargo queda vacío, se ahoga la idea de inmediatez por la que el reemplazante definitivo del presidente se encuentra permanentemente a disposición; esto es, la idea cuya importancia se vio diáfanamente reflejada en la XXv Enmienda.

Adicionalmente cabría preguntarse: ¿continúa teniendo sentido el formato electoral de fórmula presidente-vice si en cualquier momento el primero puede quitar al segundo?

Se ha de tener en cuenta también que el desplazamiento del vice sería con certeza motivo de inestabilidad para el Ejecutivo: una separación de esa índole puede ser beneficiosa a mediano o largo plazo, pero a corto plazo inevitablemente es sinónimo de agitación política. El motivo es muy sencillo: si el presidente se ve en la necesidad de expulsar al vice es porque el tándem no logró ponerse de acuerdo para que el vice renuncie de buen grado. Ahora bien, incluso teniendo en cuenta esa inestabilidad a corto plazo, la experiencia de enfrentamientos crónicos entre el presidente y un vice que hace oposición desde dentro del Ejecutivo ${ }^{28}$ debería invitar a reflexionar sobre las ventajas e inconvenientes del principio de disponibilidad.

En cuanto al segundo grado, si el presidente puede desplazar al vice y el nombramiento del sustituto es directo y obligatorio, el principio de inmediatez permanece intacto, mientras que el de disponibilidad se encuentra en un estado híbrido: no es absoluto, puesto que el presidente carece de la opción de no nombrar reemplazante, pero puede nombrar discrecionalmente a quien estime más adecuado, sin necesidad de presentar una terna al Legislativo ni de que este refrende su opción. Si tal nombramiento es directo y opcional, ambos principios se encuentran en toda su potencia.

Consideremos ahora el tercer grado: el presidente no puede quitar al vice pero puede nombrar uno nuevo si este falta. Aquí, tanto el principio de disponibilidad como el de inmediatez toman más o menos fuerza según el nombramiento de un nuevo vice sea obligatorio u optativo. En el primer caso, el de disponibilidad pierde potencia respecto del segundo grado: además de carecer el presidente de la alternativa de no nombrar un nuevo vice, tampoco puede designarlo con total discrecionalidad. Mientras tanto, el principio de inmediatez gana peso. Por el contrario, si la nominación es optativa, el termómetro de la disponibilidad sube y el de la inmediatez baja.

Por último, el cuarto grado: el presidente no puede remover al vice pero puede escoger uno nuevo si falta el titular. Puesto que se trata de la configuración estadounidense, podemos remitirnos a un ejemplo concreto para analizar sus detalles. En 1973, Spiro Agnew, vicepresidente de Richard Nixon, renunció a su puesto, ante lo cual el presidente nombró a Gerald Ford como vicepre-

28 El caso de Julio Cobos y Cristina Fernández en Argentina es paradigmático. 
sidente sustituto. Luego, la renuncia de Nixon a la presidencia situó en este cargo al propio Ford, quien, dejando la vicepresidencia vacante y en virtud de la XXV Enmienda, se vio obligado a designar a un vicepresidente: el escogido fue Nelson Rockefeller. De manera que, como consecuencia de esta Enmienda, tanto el presidente como el vice habían sido elegidos a dedo, prescindiendo de la vía electoral-democrática ${ }^{29}$. En términos de principios, resulta evidente $-\mathrm{y}$ así se ha señalado antes- que esta Enmienda procura ante todo potenciar el de inmediatez; y que, con ese fin, se posterga el de legitimidad. Igualmente se sitúa el principio de disponibilidad en un estatus híbrido, denegando al presidente la posibilidad de dejar la vicepresidencia vacante, pero permitiéndole designar al nuevo vice de manera discrecional.

\subsection{Cuatro casos de estudio}

A continuación se presentan cuatro casos. Aunque por motivos de extensión no se los estudiará en detalle, se anotarán las líneas generales que permiten relacionar el conflicto práctico con los principios teóricos aquí analizados.

\section{Oposición desde el interior del Ejecutivo}

La historia reciente de América Latina arroja varios casos de oposición al gobierno desde dentro del Ejecutivo por parte del vicepresidente. Los de Michel Temer en Brasil y Julio Cobos en Argentina son particularmente representativos por lo palpable de tal oposición: el primero se podría categorizar como destituyente, en tanto promovió la caída de la Presidente Rousseff respaldando el juicio político en su contra; el segundo no llegó tan lejos, pero pasó gran parte del mandato haciendo oposición abierta al gobierno, comenzando por un voto de desempate en el Senado en contra de un proyecto insignia del Ejecutivo.

En los dos ejemplos resultan patentes las consecuencias de la vicepresidencia rígida, esto es, de la ausencia absoluta de disponibilidad. La imposibilidad de remover al vicepresidente obligó a los presidentes a convivir con un opositor dentro del Ejecutivo: en Brasil, hasta que el vicepresidente ganó el pulso y se activó el impeachment contra Rousseff; en Argentina, hasta el final del mandato. Si bien se ha puesto en tela de juicio más arriba que la disponibilidad sea un recurso óptimo, cabe preguntarse si son preferibles las consecuencias de la indisponibilidad, tal como queda retratada en estos ejemplos.

\section{Renuncia del vicepresidente}

Cuando el vicepresidente argentino Carlos Álvarez renunció en octubre de 2000, la indisponibilidad atentó contra la inmediatez: por no poder elegir reemplazante, el Presidente De la Rúa se quedó sin un vice que pudiera

Algo casi idéntico ocurrió en Guatemala en 2015, con la salvedad de que el vicepresidente es escogido por el Congreso de una terna propuesta por el presidente, y no de manera unívoca por este (cf. A. Sribman Mittelman, La vicepresidencia en América Latina: un mal innecesario, op. cit.). reemplazarlo de manera inmediata. Además, el Ejecutivo quedó seriamente debilitado. Por una parte, porque perdió a una de sus mitades; por otra parte, porque esa mitad representaba a -y proveía el apoyo de- uno de los dos partidos que conformaban la alianza de gobierno. De manera que la salida del vice significó la fractura de la coalición. La incapacidad del presidente para nombrar un vice sustituto fue indudablemente uno de los elementos que contribuyó a la crisis política desatada tras su renuncia, que incluyó el paso de cinco presidentes provisorios por el Ejecutivo en apenas unos días (para la crisis política en torno a la caída de De la Rúa, cf. Ollier, 2008).

El caso de Álvarez retrata el vínculo multidireccional entre diversos principios: inmediatez y disponibilidad, pero también legitimidad y estabilidad, entre otros. La ausencia de disponibilidad en su segunda vertiente (la posibilidad de reemplazar la vicepresidencia vacante) atentó en el caso de Álvarez contra la inmediatez sucesoria; y en segunda instancia, eso llevó a que recayera el poder en figuras carentes de legitimidad, produciendo -en colaboración con otros factores- una coyuntura de máxima inestabilidad política.

Una vez más cabe preguntarse si la privación de disponibilidad no funge como enfermedad autoinmune del cuerpo republicano y democrático: las barreras que deberían proteger al organismo son precisamente las que lo atacan.

\section{Vicepresidente deslegitimado}

Otro tanto puede decirse de casos como el de Óscar Ortiz, vicepresidente de El Salvador entre 2014 y 2019, por citar apenas un ejemplo de vices afectados por escándalos (de corrupción o de cualquier otro tipo), y cuya permanencia en el gobierno salpicó negativamente al conjunto del Ejecutivo. No se trataba aquí de un enfrentamiento entre los dos miembros del Ejecutivo; aún así, la incapacidad del presidente de remover a su sucesor para alejar del gobierno la sombra de la corrupción vuelve a agitar el fantasma de la indisponibilidad. Esta se combinaba, en el caso de Ortiz (y en otros como el de Temer en Brasil) con cuotas de popularidad mínimas ${ }^{30}$, lo cual socava también el principio de legitimidad. Bien es cierto que el principio de inmediatez permanece vigente, aunque resulta imprescindible -en un estudio ulterior- preguntarse hasta qué extremo tiene valor este principio si aquel que sucede de manera inmediata al presidente registra índices escuálidos de legitimidad.

\section{Ni inmediatez ni disponibilidad}

El caso de Jorge Glas, vicepresidente de Ecuador entre 2013 y 2018, ejemplifica un difícil escenario en que se combinan la falta de inmediatez y de disponibilidad. Glas fue encarcelado por su implicación en el escándalo Odebrecht $^{32}$, pero se negó a renunciar. El presidente, por

30 "El $81 \%$ de la población pide que vicepresidente salvadoreño renuncie, según Iudop", El Mundo, 6 de junio de 2017. Disponible en http://elmundo.sv/el-81-de-la-poblacion-pide-que-vicepresidentesalvadoreno-renuncie-segun-iudop. 
indisponibilidad, no podía desplazarlo. Encontrándose en la cárcel, el vice no podría cumplir su función sucesoria en caso de ser necesario, de manera que tampoco se verificaba el principio de inmediatez. Esta circunstancia se extendió los 90 días que el vicepresidente ecuatoriano puede mantenerse al margen de su puesto antes de ser automáticamente apartado.

Como se ha visto en este artículo, es habitual que los principios interactúen entre sí y se contrabalanceen, de manera que la presencia o predominio de unos se corresponda con la ausencia o adelgazamiento de otros. En este caso, sin embargo, los dos principios aquí tratados se presentan en suspenso; y es conveniente hacer notar que tampoco se debe a un fortalecimiento de otros principios como el de legitimidad o el de estabilidad.

\section{Conclusiones}

Esta investigación ha partido de una comprobación empírica y una certeza metodológica: la comprobación de que la vicepresidencia se ha instaurado en casi toda América Latina sin mediar el necesario debate teórico y la correspondiente definición de conceptos fundamentales sobre los cuales asentarla; y la certeza de que esta carencia genera serios conflictos, tanto en la práctica política como en el plano simbólico.

Tampoco la Ciencia Política se había ocupado hasta ahora de abordar esta deficiencia. Por ello, este trabajo ha procurado, por una parte, proveer un marco general de acercamiento a este campo de trabajo; plantear en términos generales el problema de esta deficiencia conceptual, la relevancia de subsanarla y la necesidad de definir conceptualmente los fundamentos en que se asienta la vicepresidencia. Por otra parte, en un plano más concreto ha propuesto un acercamiento a dos de esos principios, a saber, la inmediatez y la disponibilidad.

Para comprender el alcance de estos conceptos, han sido presentados a la luz de su concepción en los albores de la Edad Moderna, y se ha indagado en su aplicación práctica -a la monarquía tardomedieval y renacentistapara cifrar adecuadamente su encaje en las instituciones contemporáneas -concretamente en la vicepresidencia estadounidense y su heredera latinoamericana.

En términos normativos, se ha advertido la necesidad de contar con principios a la hora de (re)diseñar el entramado institucional de cualquier país, y se ha verificado la ausencia de tales fundamentos teóricos en el caso de la vicepresidencia en América Latina. Ello ha dejado al descubierto la falta de respuesta para algunas preguntas esenciales: cuando la vicepresidencia es origen de graves conflictos políticos, ¿se puede defender su permanencia en la arquitectura constitucional del país en cuestión? ¿Hay algún principio que justifique su arraigo más allá de algunas coyunturas que parecerían sugerir la conveniencia de su eliminación? ¿Son tales conflictos males menores frente a ciertos bienes que trae aparejada la vicepresidencia? Y en ese caso, ¿cuáles son los principios que respaldan y explican esos bienes?

Respecto de la disponibilidad, se ha observado que su ausencia obstaculiza la solución a numerosos y serios problemas, en nombre de impedir al presidente determinados abusos de poder. En cuanto a la inmediatez, se ha visto que suele constituir la contracara de la indisponibilidad, en tanto la incapacidad del presidente para remover al vice suele tener como efecto -buscado o colateral- la permanencia del sucesor en el Ejecutivo, aún en casos en los que parecería aconsejable -para la paz interna del Ejecutivo- su remoción.

El presente trabajo supone apenas una primera y muy limitada aproximación a los fundamentos teóricos de la vicepresidencia. No obstante, ha procurado justificar la necesidad de que dichos fundamentos sean abordados en mayor extensión y detalle por estudios ulteriores; ha intentado echar luz sobre las consecuencias de conocer -y de desconocer-tales principios, tanto en el terreno teórico como en la práctica política. Es de esperar, por lo tanto, que el reciente crecimiento del interés por la vicepresidencia incluya esta vía de trabajo en su futuro desarrollo. En este sentido, una vía de gran interés para futuros trabajos consistirá en el análisis de otros principios teóricos que, como los de disponibilidad e inmediatez, pueden ayudar a explicar la presencia de determinadas instituciones en los entramados constitucionales de nuestros países.

\section{Bibliografía}

Bidegain, G., "Vicepresidentes en América del Sur: una agenda de investigación”, Colombia Internacional, 89, 2017, pp. 159188.

Bodin, J., Los seis libros de la república, Madrid, Tecnos, 1985.

Bolívar, S., "Discurso del Libertador al Congreso Constituyente de Bolivia", Pensamiento Constitucional, 2, 1995, pp. $235-243$.

Borja y Borja, R., Las Constituciones del Ecuador, Madrid, Ediciones Cultura Hispánica, 1951.

Demicheli, A., Formación constitucional rioplatense, Montevideo, Barreiro y Ramos, 1955.

Diderot, D., Escritos políticos, Madrid, Centro de Estudios Constitucionales, 1989.

Filmer, R., Patriarcha o El poder natural de los Reyes, Madrid, Espasa, 1920.

Gandía, E., San Martín. Su pensamiento politico, Buenos Aires, Pleamar, 1964.

Guillot, O., Rigaudière, A. y Sassier, Y., Pouvoirs et institutions dans la France medieval. Des temps féodaux aux temps de l'État, París, Armand Colin, 1994.

Hobbes, T., Elementos de Derecho Natural y Político, Madrid, Centro de Estudios Constitucionales, 1979.

Kantorowicz, E., Los dos cuerpos del rey, Madrid, Akal, 2012.

31 “Arrestan al vicepresidente de Ecuador por el escándalo de corrupción de Odebrecht”, La Nación, 3 de octubre de 2017. Disponible en https://www. lanacion.com.ar/2068741-arrestan-al-vicepresidente-de-ecuador-por-el-escandalo-de-corrupcion-de-odebrecht. 
Maquiavelo, N., Discursos sobre la primera década de Tito Livio, Madrid, Alianza, 2000.

Mariana, J., La dignidad real y la educación del rey, Madrid, Centro de Estudios Constitucionales, 1981.

Mariñas Otero, L., Las Constituciones de Guatemala, Madrid, Instituto de Estudios Políticos, 1958.

Marsteintredet, L., "La vicepresidencia y los problemas de la sucesión presidencial en América Latina. Viejos y nuevos retos para el presidencialismo", Política y gobierno, xxvı, 2019, pp. 117-137.

- y Uggla, F., “Allies and Traitors: Vice-Presidents in Latin America”, Journal of Latin American Studies, 1-28, 2019.

Mieres, P., "Las candidaturas vicepresidenciales en las campañas electorales. El caso de Uruguay 2009", ponencia presentada en el Cuarto Congreso de Ciencia Politica de Uruguay, 2012.

- y Pampín, E., "La trayectoria de los vicepresidentes en los regímenes presidencialistas de América", Revista de Estudios Políticos, 167, 2015, pp. 99-132.

Ollier, M. M., "La institucionalización democrática en el callejón: la inestabilidad presidencial en Argentina (1999-2003)”, América Latina Hoy, 49, 2008, pp. 73-103.

Pareja Paz-Soldán, J., Las Constituciones del Perú, Madrid, Ediciones Cultura Hispánica, 1954.

Pignataro, A. y Taylor-Robinson, M. M., "Party competition, gender quotas, and enhanced inclusiveness in the selection of vicepresidential candidates", Politics, Groups, and Identities, 2019.

Serrafero, M. D., El poder y su sombra. Los vicepresidentes, Buenos Aires, Editorial de Belgrano, 1999.

-, "Hacia una nueva vicepresidencia. Reflexiones desde el caso norteamericano", Revista de Derecho Político, 88, 2013, pp. 367-392.

-, "La Vicepresidencia y las coaliciones políticas: el caso de Argentina", Revista de Sociologia e Política, 65, 2018, pp. 15-38.

Spinoza, B., Tratado político, Madrid, Alianza, 1986.

Sribman Mittelman, A., "La Vicepresidencia Argentina (1983-2009)", Cadernos de Estudos Latino-Americanos 10, 2011.

-, La sucesión del poder. Una aproximación general desde experiencias de los siglos XX y XXI, Salamanca, Ediciones Universidad, 2015.

-, "La vicepresidencia en América Latina: un mal innecesario", América Latina Hoy 81, 2019, pp. 51-75.

-, "La vicepresidencia en México: un debate pendiente", Revista Estudios Políticos 48, 2019, pp. 73-94.

Trigo, C. F., Las Constituciones de Bolivia, Madrid, Instituto de Estudios Políticos, 1958.

Uggla, F., "The politics of vice-presidential selection in Latin America", Electoral Studies, 65, 2020.

Yerga de Ysaguirre, M. C., "Los fundamentos filosóficos de las ideas económicas de Manuel Belgrano (1770- 1820)", Revista de la Facultad de Ciencias Económicas, 121, 2000, pp. 121-136.

Zapata, R., Libros que leyó el Libertador Simón Bolivar, Santafé de Bogotá, Instituto Caro y Cuervo, 1997. 
